Diabetologia 10, 671-677 (1974)

(C) by Springer-Verlag 1974

\title{
Diabetes in Macaca nigra: Metabolic and Histologic Changes
}

\author{
Ch. F. Howard, Jr. \\ Oregon Regional Primate Research Center, Beaverton, Oregon, USA
}

Summary. Expanded studies on the spontaneous diabetes mellitus in Macaca nigra provide additional support to analogies between this animal model and human diabetes. Abnormal signs include hyperglycemia, decreased clearance of glucose in intravenous tolerance tests, reduced insulin secretion and increased serum lipids (triglyceride, prebetalipoprotein and nonesterified fatty acids). Insulin secretory capacity is lost concomitant with amyloid infiltration into the islets of Langerhans; additional metabolic aberrations may also reduce insulin secretion or action. Secondary manifestations are atherosclerosis, thickened basement membranes of muscle capillaries, and cataracts. In all probability, a genetic predisposition in these monkeys is exacerbated by changes in diet and environment.

Key words: Spontaneous diabetes, Macaca nigra, capillary basement membrane, cataracts, atherosclerosis, amyloid

\section{Introduction}

A high incidence of spontaneous diabetes mellitus has been found in Macaca nigra (Celebes black apes) [1]. Although diabetes has been diagnosed in occasional members of several non-human primate species [2-7], more than $50 \%$ of the Macaca nigra present diabetic signs of apparently increasing frequency and severity. This syndrome has now been further characterized as more monkeys become available and as more colony members are examined over a span of several years. In this report, more detailed information is presented in respect to metabolic and morphologic abnormalities.

\section{Materials and Methods}

A colony of Macaca nigra (Celebes black apes) at the Oregon Primate Center has been surveyed. 53 monkeys were studied after an overnight fast of $16 \mathrm{~h}$ for serum levels of glucose, immunoreactive insulin (IRI), triglycerides and lipoproteins. In addition, intravenous glucose tolerance tests $(0.5$ or $1.0 \mathrm{~g}$ glucose per kilogram body weight) were performed after a $20 \mathrm{~h}$ fast and the glucose disappearance rate $\mathrm{K}^{1}$ [8] from the blood was calculated.

Blood glucose was measured using a Technicon Autoanalyser. IRI was determined by radioimmunoassay [9] (Amersham/Searle, Inc.). Triglycerides were measured by the method of Pinter [10] (Worthington Biochemical Corp., New Jersey) and lipoproteins were separated on agarose gel electrophoresis [11] (Pol E-Film, Pfizer Diagnostic Co.) and stained with

$1 \mathrm{~K}=\frac{0.693 \times 100}{\mathrm{t}_{\frac{1}{2}}}=\%$ decrease per minute where $\mathrm{t}_{\frac{1}{2}}$ is the time (in minutes) for the glucose concentration to decrease to half.
Fat Red 7B. The percentage of lipoprotein bands was determined by densitometry scanning.

Pancreas samples were removed by biopsy or taken at autopsy, fixed in Zenker's solution and stained by standard techniques. Aortas were fixed in formaldehyde until they could be stained with Sudan IV. Muscle biopsies of the left femoral quadriceps were taken from 12 male and 8 female mature monkeys (more than 10 years of age), fixed in $2 \%$ osmium tetroxide in $0.05 \mathrm{M}$ collidine buffer, $\mathrm{pH} 7.4$ for $2 \mathrm{~h}$, subjected to rapid alcohol dehydration and embedded in araldite epoxy resin. Muscle capillaries were studied by electron micrographs at a total magnification of $25000 \times$. They were evaluated according to the method of Siperstein [12]. Basement membranes were measured between the outer periphery of the endothelial cells and the collagen fibrils, where they were present. All electron microscopy was done by one person. A second person measured enough points of basement membrane thickness to accumulate 100 to 200 individual measurements per monkey, and a third person carried out statistical analyses.

\section{Results}

\section{Population Characteristics, Incidence of Diabetes, Meta- bolic Abnormalities}

53 monkeys of the colony were studied by all 4 tests: levels of glucose, IRI and triglycerides, and disappearance rate $\mathrm{K}$ for glucose during intravenous glucose tolerance tests. Values were called "abnormal" at glucose $>125 \mathrm{mg} / 100 \mathrm{mI}$, IRI $<20 \mu \mathrm{U} / \mathrm{ml}$, triglycerides $>150 \mathrm{mg} / 100 \mathrm{ml}$ and a $\mathrm{K}$ value $<1.0 \%$ per min. A monkey was classified as "diabetic" when three of the tests were abnormal. An animal with one or two abnormal tests was called "borderline diabetic". According to these criteria 9 animals were found to be 
diabetic, 17 borderline diabetic and 27 monkeys were classified as "normal", as shown in Fig. 1.

Typical patterns of intravenous glucose tolerance tests with the concomitant insulin responses are shown in Fig. 2. Although the peak glucose values differ little between normal and diabetic monkeys, the insulin responses to the glucose challenge were characteristically delayed in borderline diabetic animals (No. 531 and No. 579) and almost nonexistent in diabetic apes (No. 537). As expected, there was a delay in glucose disappearance with a correspondingly lower $\mathrm{K}$ value (Fig. 2).

As serum lipids are generally lower in monkeys than in humans [13] the upper limit of normal tri- glyceride was set at $150 \mathrm{mg} / 100$. Increased levels in diabetic monkeys were generally reflected by an increase in prebetalipoprotein. Fig. 3 shows representative electrophoretic patterns. In diabetic serum (No. 537) as much as $44 \%$ of lipoprotein was found in the prebeta area. Nonesterified fatty acids were also found in higher concentration in diabetic monkeys $(1200 \mu \mathrm{eq} / \mathrm{l}$ versus $800 \mu \mathrm{Eq} / \mathrm{l}$ in normal animals [13].

\section{Morphologic Findings \\ Pancreatic Islets}

At autopsy, varying degrees of amyloid infiltration were found in the islets of adult apes. Most often the

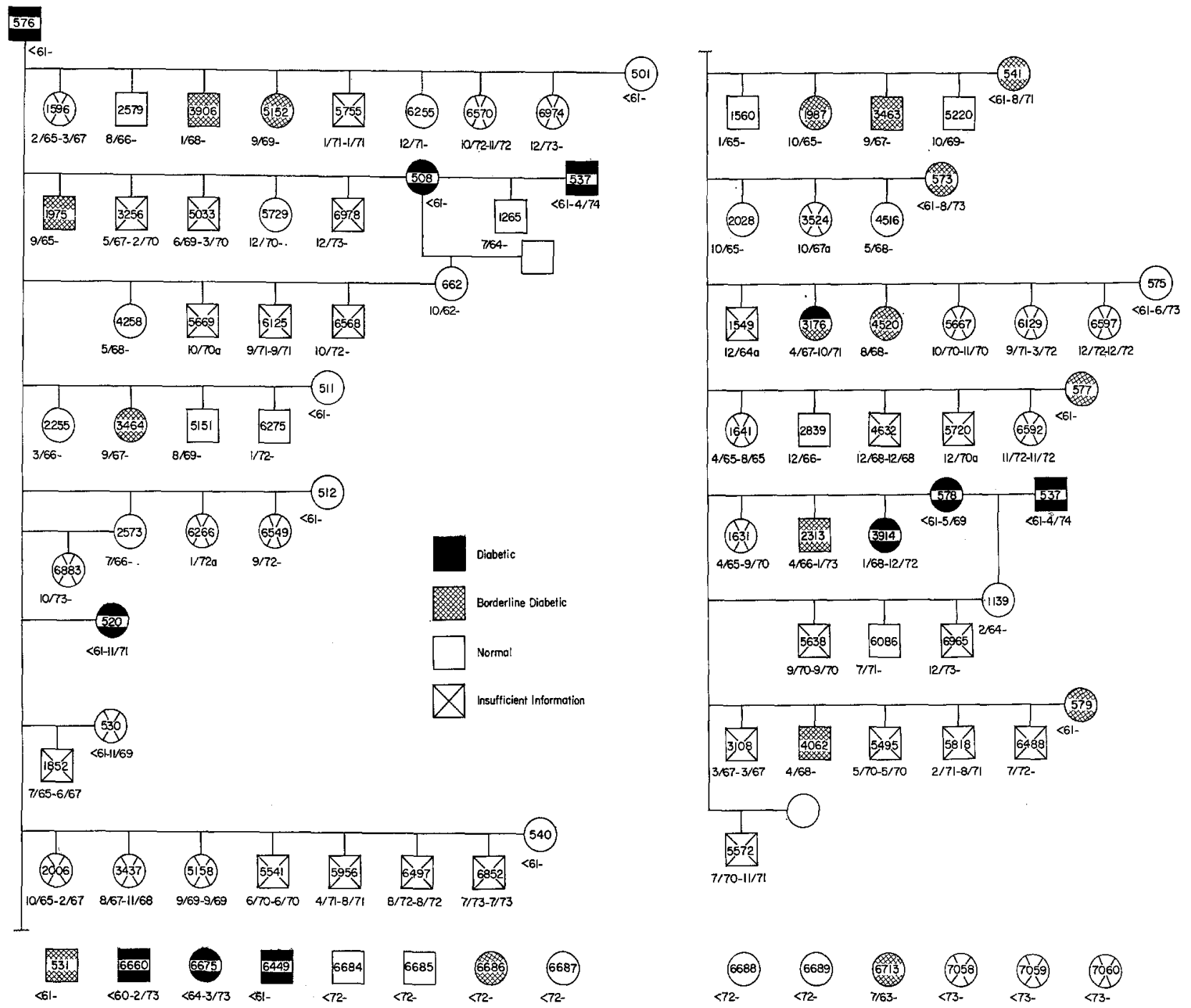

Fig. 1. Pedigree and information about Macaca nigra at the Oregon Regional Primate Research Center, December 1961 to April 1974. $\square=$ males; $O=$ females. No. 576 has mated with the females to produce the offspring indicated. Two matings are attributed to No. 537; this male was later removed from the colony to prevent conflicts with dominant male No. 576. Those with separate symbols at the bottom have no known relationship to the rest of the colony. $X$ (insufficient information) refers to monkeys which could not be tested sufficiently to attribute thera to a given group 
degree of infiltration paralleled severity and duration of diabetes. Fig. $4 \mathrm{~b}$ shows infiltration in comparison to an islet of a non-diabetic monkey (Fig. 4a). Some cells still appear viable in the amyloid infiltrated pancreas (Fig. 4b) but IRI production was so low in betic animals showed only minor changes such as some wall thickening with moderate sudanophilic blush (Fig. 5, Monkey No. 511). Animals with borderline diabetes presented varying amounts of vascular damage.

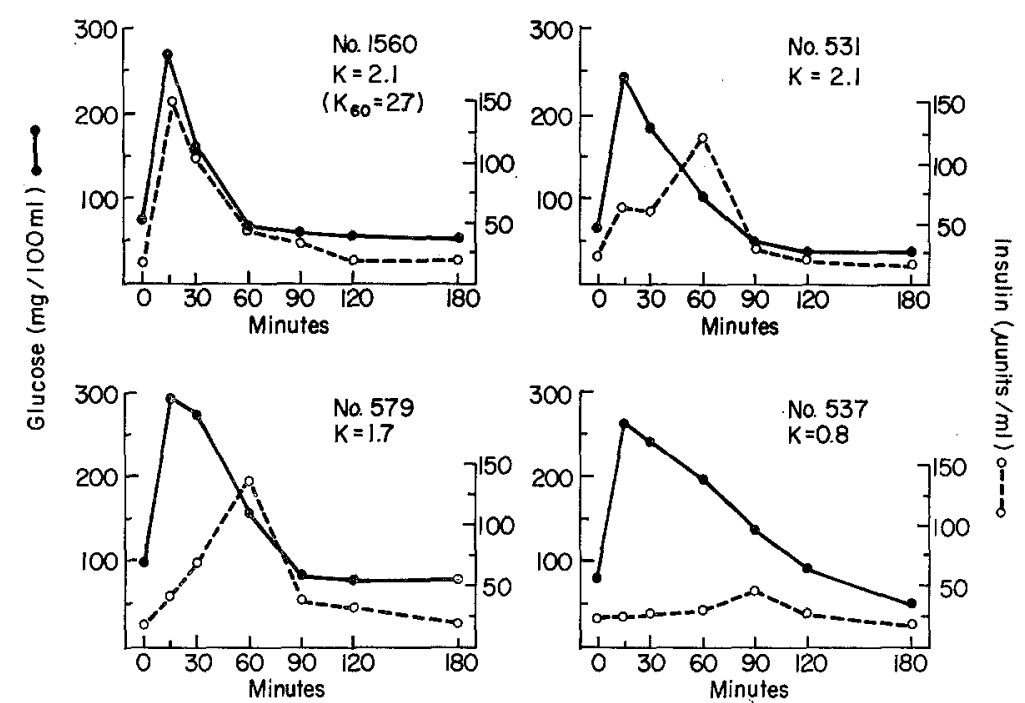

Fig. 2. Representative intravenous glucose tolerance tests in normal (upper left panel), borderline diabetic (upper right and lower left panels) and diabetic (lower right panel) Celebes black apes

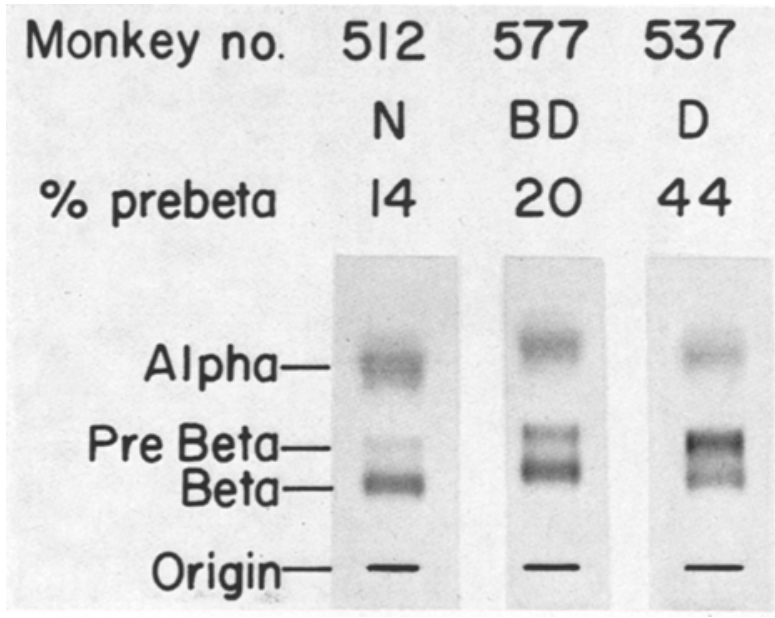

Fig. 3. Agarose gel electrophoresis of serum lipoproteins. $\mathrm{N}=$ normal $; \mathrm{BD}=$ borderline; $\mathrm{D}=$ diabetic Macaca nigra. $\%$ prebeta is the percent of lipoprotein present as prebetalipoprotein

this particular monkey that insulin therapy was necessary.

\section{Aorta}

Atherosclerosis of the aorta was much more pronounced in diabetic animals [14]. Extensive lipid and fibroelastic lesions were observed, with involvement of the entire length of the aorta as exemplified in Fig. 5. (Monkey No. 520). Arteries from non-dia-

\section{Basement Membranes of Muscle Capillaries}

As shown by Siperstein et al. [12] in human diabetes, spontaneously diabetic apes exhibited significantly ( $p=0.02$ ) thicker basement membranes of muscle capillaries. (820 Ångstroms in diabetic versus 696 Angstroms in normal animals). A representative capillary is shown in Fig. 6. As well as all over thickening of the basement membrane in diabetic apes, there was a considerable variation in thickness observed within one circumference of a given capillary. In an effort to seek a causative factor for the thickened basement membrane, correlation studies were undertaken as shown in Table 1. Significant simple correlations were found between the basement membrane thickness and the serum levels in overnight fasted

Table 1. Simple linear regression analysis between capillary basement membrane thickness and fasting serum levels of IRI, glucose and triglyceride as well as K-value in Macaca nigra

\begin{tabular}{lrl}
\hline $\begin{array}{l}\text { Basement membrane } \\
\text { thickness versus: }\end{array}$ & $\mathrm{r}$ & $\mathrm{p}$ \\
\hline IRI & -0.695 & 0.005 \\
Glucose & 0.720 & 0.003 \\
Triglyceride & 0.575 & 0.02 \\
K-value & -0.467 & $\mathbf{0 . 0 7}$ \\
\hline
\end{tabular}

Number of monkeys was 16 for all correlations.

$r=$ sample correlation coefficient.

$p=$ probability computed from a two-tailed test. 
animals of triglyceride, glucose and IRI. The closest correlation ( $\mathrm{r}=0.720 ; p=0.003$ ) was observed for serum glucose. In contrast, glucose tolerance (K value) was not significantly correlated with basement membrane thickness. Of the 16 monkeys biopsied for measurements of the thickness of the muscle capillary basement membrane, 8 were normal and 4 diabetic.
Fasting glucose levels averaged $205 \mathrm{mg} / 100 \mathrm{ml}$ in the diabetic versus $73 \mathrm{mg} / 100 \mathrm{ml}$ in the nondiabetic $(p=0.002)$. Serum insulin was decreased from $27 \mu \mathrm{U} / \mathrm{ml}$ in normal to $12 \mu \mathrm{U} / \mathrm{ml}$ in diabetic monkeys $(p<0.001)$. Triglycerides had a mean of $219 \mathrm{mg} / 100 \mathrm{ml}$ in diabetic monkeys versus $84 \mathrm{mg} / 100 \mathrm{ml}$ in nondiabetics $(p<0.001)$, and finally, $\mathrm{K}$ values of diabetic
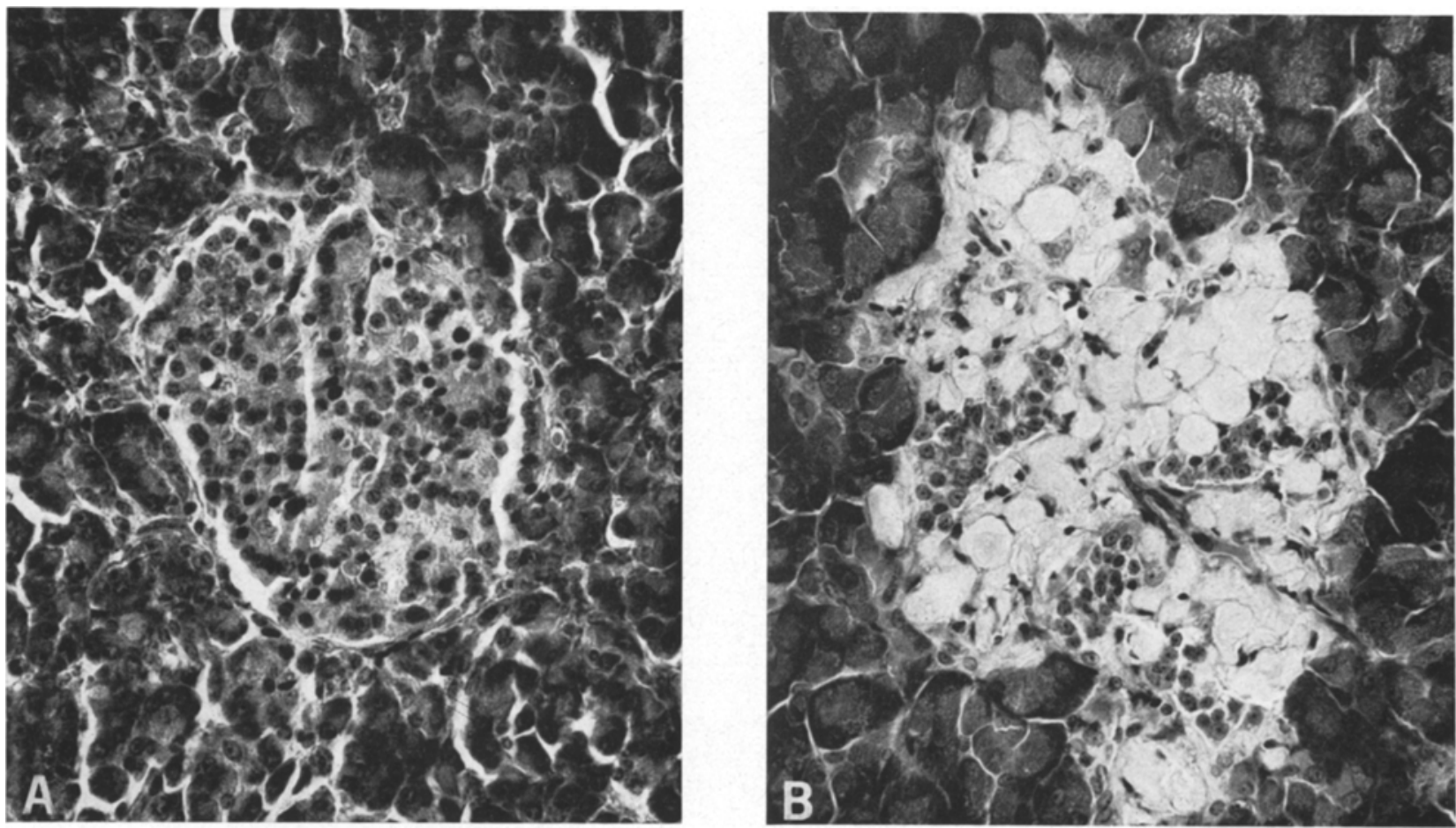

Fig. 4. Islet of Langerhans from a normal (A) and diabetic (B) monkey. There is extensive amyloid infiltration in. B and few viable cells are visible. (Hematoxylin and eosin, original magnification $335 \times$ )
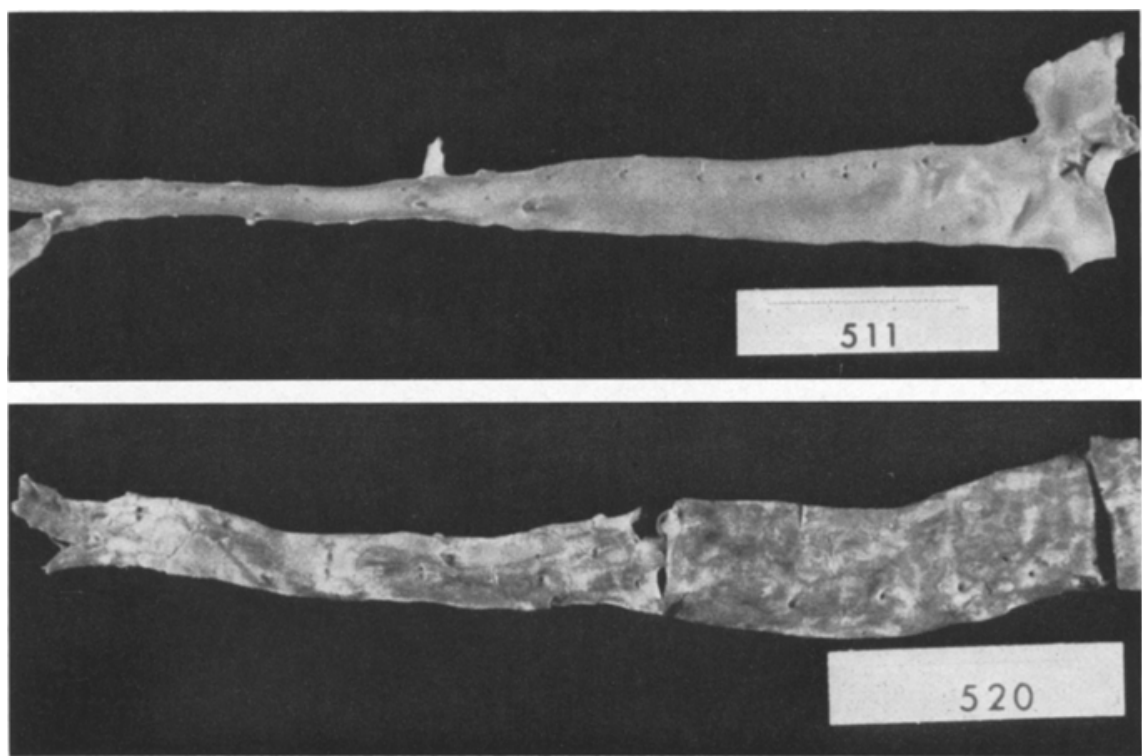

Fig. 5. Aorta from a normal (No. 511) and diabetic (No. 520) Macaca nigra. (Sudan IV staining) 
monkeys averaged 0.6 versus 2.1 in normal animals $(p=0.03)$.

\section{Eyes}

In one male monkey with diabetes of several years duration, bilateral cataracts developed, incapacitating the animal. Fig. 7 shows that the structure of the cataract resembles those seen in humans. After surgical removal of the lenses, the monkey again behaved normally. feature of the syndrome is an increase in serum prebetalipoproteins. This may also be due to the insufficient amount of insulin in the blood. Morphological examination has revealed a marked infiltration of amyloid in the pancreatic islets, an impressive atherosclerosis, thickened basement membranes of muscle capillaries and, in one monkey, cataracts.

As mentioned above, the insulin deficiency is most probably the major causative factor for the

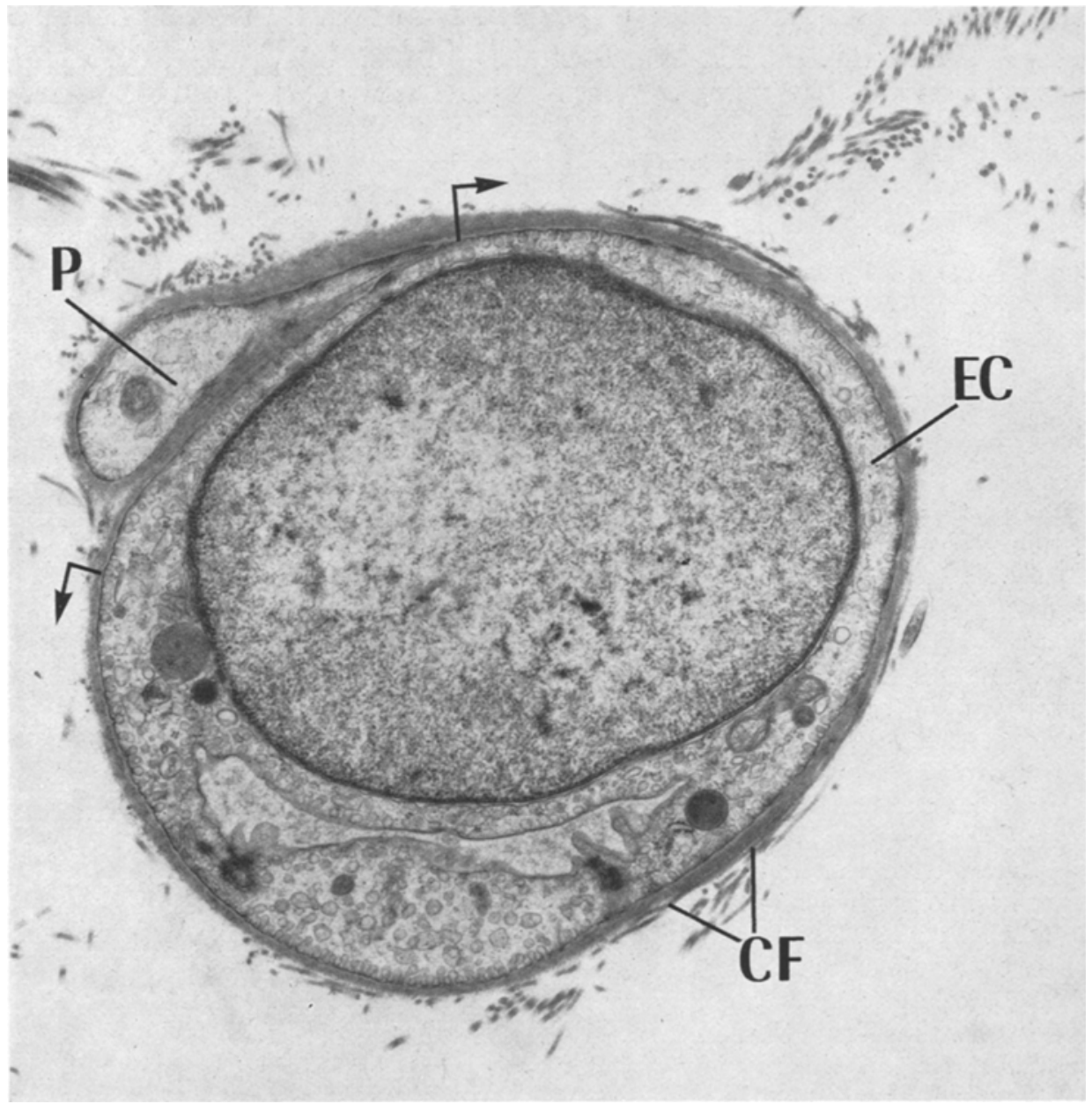

Fig. 6. Cross section of a muscle capillary of a diabetic monkey. The basement membrane is situated between the collagen fibrils and the ondothelial cell. Measurements of the basement membrane were made around the capillary between the two arrows. $P=$ pericyte; $\mathrm{EC}=$ endothelial cell $; \mathrm{CF}=$ collagen fibrils. Original magnification $25,000 \times$

\section{Discussion}

The present paper summarizes a survey of a large colony of a nonhuman primate species, Macaca nigra, in which diabetes mellitus occurs in more than half the animals. The syndrome is characterized by increased serum levels of glucose and triglyceride in the overnight fasted animals, and in a marked intolerance to glucose. The explanation of this finding is probably the insufficient release of insulin. Another metabolic metabolic abnormalities and the resultant morphological changes. The histological counterpart for this insulin deficiency lies in a serere amyloid infiltration of the islets of Langerhans. Similar infiltration has been described in other non-human primate species $[7,15]$. Is the amyloid infiltration an active primary process, or is it occurring secondary to a previous insult to the islets? Morphological studies are unable to provide the answer. Since some viable beta cells were still present within these islets, one would 
postulate some additional - perhaps metabolic factor contributing to the severity of diabetes in some monkeys (Fig. 4b).

The lack of functional beta cells is comparable to what occurs in juvenile type human diabetes and, in some instances, in adult-onset type diabetes. However the development of the full clinical picture of this monkey diabetes may require several years, whereas human juvenile type diabetes develops generally over a much shorter period. Thus an impaired ability to respond to dietary stress in these monkeys could gradually cause sufficient imbalances in metabolic homeostasis so that the diabetic signs and secondary manifestations would eventually emerge.
As most of the described lesions occur also in human diabetes, the syndrome seen in the Macaca nigra represents a particularly interesting model of diabetes mellitus.

Acknowledgments. I thank JoAnn. Wolff and Lynne Bonnett for their fine technical assistance, Audrey Griffith for electron microscopy, Dr. James Palotay of the Department of Pathology for histological procedures, and Dr. Lee Peterson, Department of Ophthalmology, University of Oregon Medical School, for consultation and cataract removal. This work was supported by grant No. HL 16661 from the National Institutes of Health and grants from the Kroc Foundation and Eli Lilly Company; additional support was provided through General Research Support Grant RR 05969 and Animal Resources

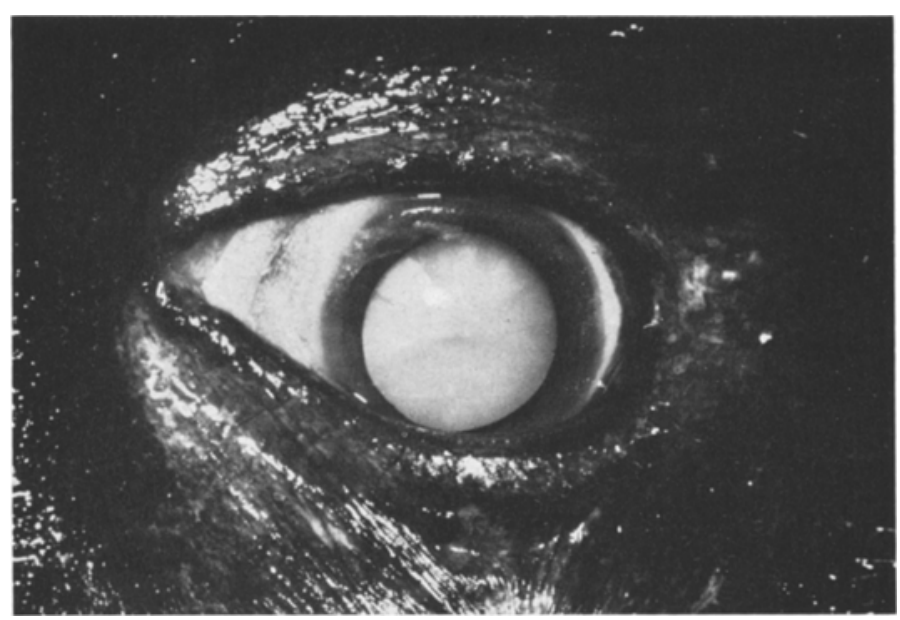

Fig. 7. Cataract development in a severely diabetic monkey

The influence of diet on the diabetic syndrome in these monkeys may be considerable. Indeed, hyperglycemia may be related to the high carbohydrate intake of the animals, as Purina $25^{\circledR}$ chow contains as much as $55 \%$ carbohydrate. The low dietary lipid content (less than $6 \%$, half of which is triglyceride and less than $0.01 \%$ cholesterol) may result in serum lipid levels lower in these monkeys than in man.

Secondary manifestations of this monkey diabetes appear to be influenced by the duration of diabetes. The severe atherosclerosis in aortas (Fig. 5) appears to parallel the alteration in the islets. Arteries, typically damaged in other diabetic syndromes, have not been studied in the present investigation. Capillaries, however, showed the typical thickening of the basement membrane as observed in human diabetes [12].

Thus far, only one monkey has developed cataracts (Fig. 7). These lesions were more often observed in monkeys made diabetic by the injection of streptozotocin [16]. It may be that the Macaca nigra of the Oregon Primate Center have not been observed over a sufficiently long period, or that their diabetic syndrome is less severe in this respect.
Branch Grant RR 00163, both from the Division of Research Resources, National Institutes of Health, to the Oregon Regional Primate Research Center. This is publication No. 726 trom the Oregon Regional Primate Research Center.

\section{References}

1. Howard, C.F., Jr.: Spontaneous diabetes in Macaca nigra. Diabetes 21, $1077-1090$ (1972)

2. Sokoloverova, I.M.: Spontaneous diabetes in a monkey. In. "Theoretical and Practical Problems of Medicine and Biology in Experiments on Monkeys," Utkin, I.A., (ed.) pp. 171-183. New York: Pergamon, Pross 1960

3. Rabb, G.B., Getty, R.E., Williamson, W.M., Lombard, L.S.: Spontaneous diabetes mellitus in tree shrews, Urogale everetti. Diabetes 15, 327-330 (1966)

4. Davidson, I. W.F., Lang, C.M., Blackwell, W.L.: Impairment of carbohydrate metabolism of the squirrel monkey. Diabetes 16, 395-401 (1967)

5. DiGiacomo, R.F., Myers, R.E., Balz, L.R.: Diabetes mellitus in a rhesus monkey (Macaca mulatia): a case report and literature review. Lab. Anim. Sci. 21, $572-574$ (1971)

6. Kirk, J.H., Casey, H. W., Harwell, J. W. Jr. : Diabetes mellitus in two rhesus monkeys. Lab. Anim. Sci. 22, $245-248$ (1972) 
7. Howard, C.F. Jr.: Spontaneous diabetes in Macaca cyclopis and Mandrillus leucophaeus: case reports. Lab. Anim. Sci. (in press)

8. Lundbaek, K.: Intravenous glucose tolerance as a tool in definition and diagnosis of diabetes mellitus. Brit. med. J. 1962 I, $1507-1513$

9. Hales, C.N., Randle, P.J.: Immunoassay of insulin with insulin-antibody precipitate. Biochem. J. 88, $137-146(1963)$

10. Pinter, J.K., Hayashi, J.A., Watson, J.A.: Enzymic assay of glycerol, dihydroxyacetone and glyceraldehyde. Arch. Biochem. Biophys. 121, 404-414(1967)

11. Noble, R.P.: Electrophoretic separation of plasma lipoprotein in agarose gel. J. Lipid Res. 9, 693-700 (1968)

12. Siperstein, M.D., Raskin, P., Burns, H.: Electron microscopic quantification of diabetic microangiopathy. Diabetes 22, 514-527 (1973)

13. Howard, C.F. Jr.: Correlations of serum triglycerides and prebetalipoprotein levels to the severity of spontaneous diabetes in Macaca nigra. J. clin. Endocr. $38,856-860(1974)$

14. Howard, C.F. Jr.: The relationship of diet and atherosclerosis in diabetic Macaca nigra. In: Diet and Atherosclerosis. Paoletti, R. (ed.). New York: Plenum Press, in press

15. Sheldon, W.G., Gleiser, C.A.: Amyloidosis of the islets of Langerhans in a crab-eating monkey (Macaca fascicularis). Vet. Path. 8, 16-18 (1971)

16. Howard, C.F. Jr.: Streptozotocin-induced diabetes mellitus by direct pancreatic infusion in Macaca nemestrina. Diabetes 21, 138-142 (1972)

Charles F. Howard, Jr., Ph.D. Oregon Regional Primate Research Center

505 N.W. 185th Avenue Beaverton, Oregon 97005 USA 